\title{
Consumption Theory with Reference Dependent Utility
}

\author{
Fredrik W. Andersson* $\dagger$
}

SEPTEMBer 2006

\begin{abstract}
This paper presents a closed form consumption function for an individual when he derives utility from both his current and previous consumption and from the consumption of his relevant others. I show that the traditional definition of an individual's marginal propensity to consume (MPC) is too narrow. With existing knowledge we would call for a broader definition of the MPC that I coin as the individual's total MPC, which also takes into account the consumption change of the relevant others, and this affects that total MPC is smaller than the traditional MPC.
\end{abstract}

JEL classification: D91, E21

Keywords: Consumption decision, consumption of relevant others, habitformation behavior, marginal propensity to consume, excess smoothness.

\section{Introduction}

Empirical evidence suggests that individuals evaluate their consumption (income) levels compared to the consumption (income) levels of others, e.g. Solnick and Hemenway (1998), Johansson-Stenman et al. (2002), Alpizar et al. (2005), and Andersson (2006). This paper presents an extended version of Alessie and Lusardi's (1997) consumption model, in which individuals merely care about their own current and previous consumption. I add the assumption that individuals also compare their own consumption with that of relevant others, and derive a closed form consumption function for an

\footnotetext{
*Göteborg University, Department of Economics, Telephone: +46 (0)31 7732679. Address: Vasagatan 1, Box 640, 40530 Göteborg, Sweden. Corresponding email address: fredrik.w.andersson@economics.gu.se

${ }^{\dagger}$ I appreciate the thoughtful comments of Katarina Nordblom, Olof JohanssonStenman, Håkan Locking, Wlodek Bursztyn, John Hassler, Markus Knell, and to Debbie Axlid for editorial advices. The usual disclaimer applies.
} 
arbitrary individual. Since the individual's consumption also depends upon the consumption of his relevant others I introduce the definition: the individual's total MPC. Earlier theories like Hall's Hall (1978) permanent income hypothesis or a pure habit formation behavior model, such as Alessie and Lusardi (1997), have both larger marginal propensities to consume than an individual that derives utility as in this model.

Is it realistic that individuals only have their own previous consumption levels as a reference-level? Probably not. From a psychological perspective, individuals compare their consumption levels also with the consumption levels of relevant others. Duesenberry (1949, p. 48) argues that "Any particular consumer will be influenced by consumption of people with whom he has social contacts..."; he coins this concept as "the demonstration effect." Duesenberry's notion has long been overlooked in economics models, although he had early advocators within psychology. For example, Runciman (1966) argues that individuals have both a space and time dimension of comparison. Frank (1985, p. 146) presents an explanation to why economists were not keen on adopting the space dimension: "To many economists, the notion of consumers being strongly influenced by demonstration effects must have seemed troublingly inconsistent with the reasoned pursuit of self-interest, if not completely irrational." It seems reasonable to extend Alessie and Lusardi's (1997) model by including Duesenberry's demonstration effect. A point in support of this is expressed by Frank (1985, p. 150) : "... concerns about relative standing are perfectly compatible with the economist's view that people pursue their own interest in a rational way." I believe this extended consumption model adds more knowledge about the individuals' actual consumption decision. ${ }^{1}$

This paper has the following structure: In the subsequent Section 2 I introduce the notion behind the individual's utility maximization problem. In Section 3, I derive the individual's closed form consumption function. Section 4 discusses the definition of the individual's MPC given different notions of how the individual derives utility and finally, in Section 5, I draw some concluding remarks.

\section{The Individual's Utility}

\subsection{The Individual's Utility Function Arguments}

In order to emphasize how important individuals' social interactions with each other are, Aristotle referred to human beings as social animals. By looking at psychological and sociological motives, e.g. Duesenberry (1949),

\footnotetext{
${ }^{1}$ I use an additive comparison function since Wendner (2002, p. 16) arguments "the multiplicative [i.e. ratio; FA] specification is not in line with elementary properties of habit persistence." Although, the additive comparison is in contrast to the ratio comparison which e.g. authors such as: Abel (1990); Carroll et al. (1997) and Carroll (2000) use.
} 
Runciman (1966), Frank (1985), and Elster and Loewenstein (1992), argue that individuals have both a space and a time dimension of comparison. I.e. individuals compare their own current consumption with a reference-level that consists of a combination of the consumption of relevant others and their own previous consumption, i.e. a combination of Alessie and Lusardi (1997) and Hall (1978). This adds more realism to how individuals derive their utility compared to these two previous consumption models. Put differently, Scitovsky (1992) argues that people wish to keep their status in relation to their reference-level, since losing status may becomes painful. Hence, I extend Alessie and Lusardi's (1997) consumption amount that drives utility with the previous consumption of relevant others. Then, the "psychological" consumption amount that drives utility at time $\tau$ for an arbitrary individual is:

$$
c_{\tau}^{*}=c_{\tau}-\gamma c_{\tau-1}-\eta \bar{c}_{\tau},
$$

where $\eta \in[0,1]$ controls how much the individual cares about the consumption of his relevant others, ${ }^{2} \bar{c}_{\tau} \cdot{ }^{3}$ A higher $\eta$ implies that the individual cares more about the previous consumption of relevant others. The other parameter $\gamma \in[0,1]$ controls how much the individual cares about his own previous consumption, and $\gamma>0$ implies that the individual has a habit-formation behavior. A higher $\gamma$ implies that the individual cares more about his previous consumption. This psychological consumption amount, (1), that drives utility is general since it nests both Hall's and Alessie and Lusardi's consumption models. From (1), if $\gamma=0$ and $\eta=0$ the individual derives utility as in Hall (1978), and if $\gamma>0$ and $\eta=0$, the individual derives utility as in Alessie and Lusardi (1997).

\subsection{The Individual's Utility Maximization Problem}

By assumption the individual's utility, $u\left(c_{\tau}^{*}\right)$, is concave, continuous and twice differentiable over the interior of the individual's $c_{\tau}^{*}$ set, and moreover I restrict the individual's consumption amount, $c_{\tau}$, to always be non-negative.

In order for the individual to optimize his consumption profile the individual's needs to predict at period $t$ his stock of human wealth, which is the present discounted value of his expected future labor income, and the current value of his non-human wealth (a). I assume that the individual has a finite life and gives no bequests at period $T$, and lives in a world with a perfect capital market (i.e. individuals can borrow and lend at the

\footnotetext{
${ }^{2}$ The consumption of relevant others refers to, for example, neighbors, co-workers, or friends.

${ }^{3}$ This is similar to the psychological consumption that Alonso-Carrera et al. (2004) use in a paper where they analyze the circumstances under which consumptions of relevant others are a source of inefficiency. They have also included a third reference argument; which is the previous consumption, $\bar{c}_{t-1}$, of relevant others.
} 
same constant ${ }^{4}$ interest rate) in addition is not liquidity constrained. Furthermore, I assume that the individual has perfect foresight about his own future labor income and the future consumption of his relevant others, i.e. the information is complete and there is no uncertainty.

Then the individual's intertemporal maximization problem can be specified as:

$$
\max _{\left\{c_{\tau}\right\}_{\tau=t}^{T}} U_{\tau}=\sum_{\tau=t}^{T} \beta^{\tau} u\left(c_{\tau}^{*}\left(c_{\tau}, c_{\tau-1}, \bar{c}_{\tau}\right)\right)
$$

subject to his intertemporal budget constraint

$$
\sum_{\tau=t}^{T}\left(\frac{1}{1+r}\right)^{\tau} c_{\tau}=a_{\tau}+\sum_{\tau=t}^{T}\left(\frac{1}{1+r}\right)^{\tau} y_{\tau} .
$$

When the interest rate, $r$, is constant over time the intertemporal budget constraint implies that the present discounted value of consumption is equal to the individual's initial wealth $(a)$ plus his present discounted labor income $(y)$.

Furthermore, I assume that the relevant others consumption is not affected by the individual's consumption, i.e. $\bar{c}_{\tau}$ is exogenously given.

The individual's subjective discount factor, $\beta=\frac{1}{1+\rho}$, is constant over time, where $\rho>0$ is the individual's subjective discount rate. This rules out any possibility of discontinuity of $U_{\tau}$, i.e. assures that $U_{\tau}$ does not diverge to infinity.

The individual's intertemporal maximization problem is then solved by maximizing the individual's lifetime utility (2) subject to his intertemporal budget constraint (3). The Lagrangian function for this problem is:

$$
\begin{aligned}
\max _{\left\{c_{\tau}\right\}_{\tau=t}^{T}} \mathscr{L}\left(c_{\tau}, c_{\tau+1}, \ldots ; \lambda\right) & =\sum_{\tau=t}^{T} \beta^{\tau} u\left(c_{\tau}^{*}\left(c_{\tau}, c_{\tau-1}, \bar{c}_{\tau}\right)\right) \\
& +\lambda\left(a_{\tau}+\sum_{\tau=t}^{T}\left(\frac{1}{1+r}\right)^{\tau} y_{\tau}-\sum_{\tau=t}^{T}\left(\frac{1}{1+r}\right)^{\tau} c_{\tau}\right)
\end{aligned}
$$

where $\lambda$ is the constant Lagrange multiplier. The first order condition for an interior solution at an arbitrary period $t$ is:

$$
\frac{\partial \mathscr{L}(.)}{\partial c_{t}}=\beta^{t} \frac{\partial u\left(c_{t}^{*}\right)}{\partial c_{t}^{*}} \frac{\partial c_{t}^{*}}{\partial c_{t}}+\beta^{t+1} \frac{\partial u\left(c_{t+1}^{*}\right)}{\partial c_{t+1}^{*}} \frac{\partial c_{t+1}^{*}}{\partial c_{t}}-\lambda\left(\frac{1}{1+r}\right)^{t}=0,
$$

Since this expression holds for all $t$ it is obvious it also holds for $t+1$ :

$$
\begin{aligned}
\frac{\partial \mathscr{L}(.)}{\partial c_{t+1}} & =\beta^{t+1} \frac{\partial u\left(c_{t+1}^{*}\right)}{\partial c_{t+1}^{*}} \frac{\partial c_{t+1}^{*}}{\partial c_{t+1}}+\beta^{t+2} \frac{\partial u\left(c_{t+2}^{*}\right)}{\partial c_{t+2}^{*}} \frac{\partial c_{t+2}^{*}}{\partial c_{t+1}}- \\
& -\lambda\left(\frac{1}{1+r}\right)^{t+1}=0
\end{aligned}
$$

\footnotetext{
${ }^{4}$ The interest rate is independent of the capital stock in the economy.
} 
Then solving for the individual's marginal rate of substitution (MRS) by combining (5) and (6), after some manipulation we have:

$$
\frac{\frac{\partial u\left(c_{t+1}^{*}\right)}{\partial c_{t+1}^{*}} \frac{\partial c_{t+1}^{*}}{\partial c_{t+1}}+\beta \frac{\partial u\left(c_{t+2}^{*}\right)}{\partial c_{t+2}^{*}} \frac{\partial c_{t+2}^{*}}{\partial c_{t+1}}}{\frac{\partial u\left(c_{t}^{*}\right)}{\partial c_{t}^{*}} \frac{\partial c_{t}^{*}}{\partial c_{t}}+\beta \frac{\partial u\left(c_{t+1}^{*}\right)}{\partial c_{t+1}^{*}} \frac{\partial c_{t+1}^{*}}{\partial c_{t}}}=\frac{1+\rho}{1+r} .
$$

Up to this point, (7), the individual's MRS is valid for both a ratio or additive comparison function. Now, I continue the derivation of the individual's MRS with the additive comparison function as in (1). Thus, eq. (1) has the following properties for the additive comparison function:

$$
\begin{aligned}
\frac{\partial c_{t}^{*}}{\partial c_{t}} & =\frac{\partial c_{t+1}^{*}}{\partial c_{t+1}}=1, \\
\frac{\partial c_{t+1}^{*}}{\partial c_{t}} & =\frac{\partial c_{t+2}^{*}}{\partial c_{t+1}}=-\gamma .
\end{aligned}
$$

With the assumption that the individual's subjective discount rate is equal the interest rate $(\rho=r)$ the individual's MRS (7) may be rewritten with the additional properties in (8) and (10) as:

$$
\frac{\frac{\partial u\left(c_{t+1}^{*}\right)}{\partial c_{t+1}^{*}}-\gamma \beta \frac{\partial u\left(c_{t+2}^{*}\right)}{\partial c_{t+2}^{*}}}{\frac{\partial u\left(c_{t}^{*}\right)}{\partial c_{t}^{*}}-\gamma \beta \frac{\partial u\left(c_{t+1}^{*}\right)}{\partial c_{t+1}^{*}}}=1 .
$$

Equation (10) is satisfied if and only if:

$$
\frac{\partial u\left(c_{t}^{*}\right)}{\partial c_{t}^{*}}=\frac{\partial u\left(c_{t+1}^{*}\right)}{\partial c_{t+1}^{*}}=\frac{\partial u\left(c_{t+2}^{*}\right)}{\partial c_{t+2}^{*}}=\Omega, \quad \forall t,
$$

where $\Omega$ is a constant (See appendix A for the proof). I.e. the marginal utility of psychological consumption must be constant over time if the MRS between any two periods should be equal to 1 . Any concave utility function implies that when the marginal utility of psychological consumption is constant the level of psychological consumption is also constant $\Rightarrow c_{\tau}^{*}=$ constant. (See Lemma 1.)

Lemma 1. Eq. (11) implies that the path of psychological consumption $\left\{c_{t}^{*}\right\}_{t=0}^{T}$ is constant over time.

Hence, the change in marginal utility with respect to the individual's utility function's arguments implies that if the consumption of relevant others increases in period $t+1$ the individual's consumption at period $t+1$ must increases in order to keep the marginal utility of psychological consumption constant over time. Utilizing this knowledge it is possible to derive the individual's consumption change:

$$
\Delta c_{t+1}=\gamma \Delta c_{t}+\eta \Delta \bar{c}_{t+1} .
$$


This shows that the individual consumption change in period $t+1$ depends on his own previous consumption change and the current consumption changes of his relevant others. ${ }^{5}$ This model nests Hall's, and Alessie and Lusardi's models, where Hall's model shows that tomorrow's consumption is equal to today's consumption (consumption is constant over time when $\gamma=0$ and $\eta=0$ ). Another case that is nested in eq. (12) is Alessie and Lusardi (1997), i.e. when $\gamma \neq 0$ and $\eta=0$, which suggests that $\Delta c_{t+1}=\gamma \Delta c_{t}$. Their Euler-equation argues that tomorrow's consumption change is equal to a fraction of today's consumption change. This implies that the individual's consumption changes goes toward zero over time - it too is constant in the long run. The last case that is nested of eq. (12) is when $\gamma=0$ and $\eta=1$, which implies that tomorrow's consumption change of the individual is equal to a fraction of the current consumption change of his relevant others.

\section{The Individual's Closed Form Consumption Func- tion}

In order to discus the aim of this paper I need to derive a closed form consumption function for the individual. Hence, I rewrite the intertemporal budget constraint (3) by substituting in $c_{\tau}$ from (1) and after some manipulation I solve for the present discounted value of $c_{\tau}^{*}: 6$

$$
\begin{array}{r}
\sum_{\tau=t}^{T}\left(\frac{1}{1+r}\right)^{\tau} c_{\tau}^{*}=-\gamma c_{\tau-1}-\eta \sum_{\tau=t}^{T}\left(\frac{1}{1+r}\right)^{\tau} \bar{c}_{\tau}+ \\
+\left[1-\frac{\gamma}{1+r}\right]\left(a_{\tau}+\sum_{\tau=t}^{T}\left(\frac{1}{1+r}\right)^{\tau} y_{\tau}\right) .
\end{array}
$$

\footnotetext{
lem.

${ }^{5} \mathrm{My}$ only interest here is the interior solution to the intertemporal maximization prob-

${ }^{6}$ We can easily verify that if $\gamma=0$ the intertemporal budget constraint collapses to an ordinary "textbook" intertemporal budget constraint and hence, if $\alpha=0$ it collapses to Alessie and Lusardi's (1997) intertemporal budget constraint.
} 
Using Lemma 1, I can derive from (13) the individual's closed form consumption function: ${ }^{7}$

$$
\begin{aligned}
c_{\tau}= & \underbrace{\frac{(1+r)^{T}-1}{(1+r)^{T+1}-1} \gamma c_{\tau-1}}_{i}+\underbrace{\frac{(1+r)^{T}-1}{(1+r)^{T+1}-1} \eta \bar{c}_{\tau}}_{i i}- \\
& -\underbrace{\eta \frac{r(1+r)^{T}}{(1+r)^{T+1}-1} \sum_{\tau=t+1}^{T}\left(\frac{1}{1+r}\right)^{\tau} \bar{c}_{\tau}}_{i i i}+ \\
& +\underbrace{\left(1-\frac{\gamma}{1+r}\right) \frac{r(1+r)^{T}}{(1+r)^{T+1}-1}\left[a_{\tau}+\sum_{\tau=t}^{T}\left(\frac{1}{1+r}\right)^{\tau} y_{\tau}\right]}_{i v} .
\end{aligned}
$$

From Eq. (14) follows that the individual's consumption level at time $\tau$ depends on four features: $(i)$ a habit level of consumption - the individual's own previous consumption, (ii) a keeping up effect - current consumption of the relevant others, (iii) a fear (future potential disutility) of falling behind effect - the future consumption of the relevant others, and (iv) the wealth effect which is also present in the permanent income hypothesis (PIH), although it is reduced when the individual has a habit-formation behavior $(\gamma>0) .{ }^{8}$ This general closed form consumption function eq. (14) nests two (specific) other consumption functions found in the literature. For example, when $\gamma=0$ we have Hall's (1978) consumption function, which shows that an individual's consumption at time $\tau$ is equal to the annuity value of his lifetime resources - the permanent income - and is constant over time. The other extreme case is when $\gamma>0$ and $\eta=0$. This corresponds to the consumption function of Alessie and Lusardi (1997), where the individual's consumption at time $\tau$ depends partly on his previous consumption and partly on his permanent income.

\subsection{The Impact from the Individual's Permanent Income}

It is possible to rewrite eq. (14) by using concepts such as the individual's permanent income and the permanent consumption of his relevant others, ${ }^{9}$ where the individual's permanent income $\left(y_{\tau}^{p}\right)$ is the annuity value of the sum of the current non-human wealth $\left(a_{\tau}\right)$ and human wealth (present discounted value of future income), and where the permanent consumption of relevant

\footnotetext{
${ }^{7}$ We know that Lemma 1 implies $\sum_{\tau=t}^{T}\left(\frac{1}{1+r}\right)^{\tau} c_{\tau}^{*}=\frac{(1+r)^{T+1}-1}{r(1+r)^{T}} c_{\tau}^{*}$.

${ }^{8}$ The number of lagged variables depends on how many lagged variables are included in the $c_{\tau}^{*}$ measure.

${ }^{9}$ Although, it would be possible to rewrite the permanent consumption of the relevant others as permanent income is we assume a constant saving rate.
} 
others $\left(\bar{c}_{\tau+1}^{p}\right)$ is the annuity value of the present discounted value of future consumption. Thus, the individual's closed form consumption function is:

$$
c_{\tau}=\gamma \Psi c_{\tau-1}+\eta \Psi \bar{c}_{\tau}-\eta \bar{c}_{\tau+1}^{p}+\left(1-\frac{\gamma}{1+r}\right) y_{\tau}^{p},
$$

where $\Psi=\frac{(1+r)^{T}-1}{(1+r)^{T+1}-1}, y_{\tau}^{p}=\frac{r(1+r)^{T}}{(1+r)^{T+1}-1}\left(a_{\tau}+\sum_{\tau=t}^{T}\left(\frac{1}{1+r}\right)^{\tau} y_{\tau}\right)$, and $\bar{c}_{\tau+1}^{p}=$ $\frac{r(1+r)^{T}}{(1+r)^{T+1}-1} \sum_{\tau=t+1}^{T}\left(\frac{1}{1+r}\right)^{\tau} \bar{c}_{\tau}$.

We can see from (15) that a change in permanent income has the same affect on the individual's consumption as if psychological consumption measure would merely include a habit formation behavior, i.e. the individual's utility is driven by $c_{\tau}^{*}=c_{\tau}-\gamma c_{\tau-1}$. Thus, the individual's consumption changes with the individual's permanent income as:

$$
\frac{\partial c_{\tau}}{\partial y_{\tau}^{p}}=1-\frac{\gamma}{1+r}
$$

From eq. (16) we can see that if the individual increases his concern about his previous consumption, i.e. his habits, a change in his permanent income changes his consumption lesser.

$$
\frac{\partial^{2} c_{\tau}}{\partial y_{\tau}^{p} \partial \gamma}=-\frac{1}{1+r}<0
$$

When the individual has a negative change in his permanent income, stronger habits (higher $\gamma$ ) implies that the individual's consumption reduces with a smaller amount than if his habits were not that strong. This smoother reduction comes from the fact that it takes time before the individual alters his consumption habits.

\subsection{The Impact from the Consumption of Relevant Others}

If the individual, at time $\tau$, cares more about the consumption of his relevant others his consumption changes according to

$$
\frac{\partial c_{\tau}}{\partial \eta}=\underbrace{\Psi \bar{c}_{\tau}}_{i i}-\underbrace{\bar{c}_{\tau+1}^{p}}_{i} .
$$

The individual's consumption is affected in two ways: $(i)$ one effect comes from the relevant others' future consumption path that the individual will infer as painful - i.e. reduced utility. This is catched by last term in (18) where we can see how the individual's consumption is negatively affected from his relevant others' future consumption. Hence, the higher the future permanent consumption of his relevant others are, the more the individual's consumption at time $\tau$ is reduced. (ii) The second effect comes for that 
the individual's wish to keep up with the consumption levels of his relevant others at time $\tau$; which is catched by the first term in (18). This implies that the individual's consumption level adjusts upward by a fraction of the current consumption of relevant others. I.e. the individual's consumption tracks - keeps up - to some degree the consumption of his relevant others.

\subsubsection{A Temporal Increase in the Consumption of Relevant Oth- ers}

A temporal increase in the consumption of relevant others at current time, $\tau$, may be for example a bonus, i.e. an extra amount of money, that is not expected to come next time period. This increase in current consumption of his relevant others increases the individual's current consumption, since he wishes to keep up with his relevant others

$$
\frac{\partial c_{\tau}}{\partial \bar{c}_{\tau}}=\eta \Psi>0
$$

This effect may have an affect on the individual's consumption growth, and hence may provide some insight to why consumption grows higher than income is growing.

"... in each of the past three years, real consumer outlays have grown faster than real aftertax income."

- Business Week 17/4 2006 (U.S.: It's Way Too Early To Count Consumers Out)

The individual knows that the consumption of relevant others increases at time $\tau$ but not at time $\tau+1$. Therefore he will increase his consumption at time $\tau$ - in this way he does not painfully loss status.

\subsubsection{A Permanent Increase in the Consumption of Relevant Others}

Veblen (1934) states that it is the best-off members in the society that establish the consumption standard for the rest and then people below wish to emulate their consumption. Duesenberry (1949, p. 101) claims that "Low-income groups are affected by consumption of high-income groups but not vice versa." I.e. individuals make an upward comparison when they evaluate their consumption level. Similar thoughts, i.e., upwards comparison are today voiced by e.g. Schor (1998, p. 4) who argues that individuals today "make comparison with, or choose a 'reference group,' people whose income are three, four, or five times his or her own". She finds that individuals that have less financial status than their reference-group saves significantly less than those individuals that have a better financial status than their reference-group. 
If the increase in the consumption of his relevant others is permanent, i.e., also $\bar{c}_{\tau+1}^{p}$ changes not merely $\bar{c}_{t}$ changes, the individual's consumption changes as:

$$
\frac{\partial c_{\tau}}{\partial \bar{c}_{\tau}}+\frac{\partial c_{\tau}}{\partial \bar{c}_{\tau+1}^{p}}=\eta \Psi-\eta=\eta(\Psi-1)<0, \text { since } \Psi<1 .
$$

Hence, the individual's consumption is negatively effected from a permanent consumption increase by the relevant others. This comes from that an increase in the current consumption of his relevant others increases the individual's consumption with $\eta \Psi$. On the other hand, an increase in the permanent consumption of relevant others decreases the individual's current consumption. ${ }^{10}$

\section{Marginal Propensity to Consume}

\subsection{A Review of Marginal Propensity to Consume}

Keynes (1936, p. 36) argues that "The fundamental psychological law ... is that men are disposed, as a rule and on the average, to increase their consumption as their income increases, but not by as much as the increases in their income". Hence, the Keynesian consumption function hypothesizes that if an individual's current income rises/falls by one unit, then his consumption should rise/fall proportionally with the MPC, which is less than 1. This is the absolute income hypothesis. Another venue is Friedman (1957) permanent income hypothesis, where MPC is determined by the relative variations in permanent and transitory incomes. When the variation in permanent income is much greater than the variation in transitory income, consumption rises almost one-for-one with current income. Intuitively, an individual's consumption increases when his permanent income increases. Hall (1978) derives his version of the permanent income hypothesis (PIH) within a framework of explicit intertemporal utility maximization, rather than merely asserting a proportional dependence between consumption and permanent income, and predicts that the MPC is one. Thus, any change in the individual's permanent income affects his consumption one-for-one. Duesenberry (1949) rejects this symmetric notion, claiming that once consumption habits and status are acquired, it is hard for the individual to alter them. He therefore postulates the relative income hypothesis. At certain income levels certain consumption habits and status are formed which are not completely abandoned if income falls; it takes time for individuals to adjust consumption downward. Alessie and Lusardi (1997) derive a closed

\footnotetext{
${ }^{10}$ This effect is a result from the individual's intertemporal budget constraint; which implies that his present discounted value of consumption cannot be larger than the present discounted value of his human, and non-human wealth.
} 
form consumption function from Duesenberry's (1949) notion. The implication is that when an individual cares both about his current and previous own consumption, his MPC is smaller than in Hall's (1978) model of PIH. Although I use perfect foresight about future flows, the MPC is the same as if the individual would have a stochastic labor income process.

We are now ready to compare the different marginal propensities to consume from Hall's (1978) model of PIH, Alessie and Lusardi (1997) and my eq. (15).

\subsection{The Individual's Marginal Propensity to Consume}

After deriving the individual's closed form consumption function it is now possible to derive and study the individual's marginal propensity to consume. The traditional definition of an individual's MPC is:

$M P C$ defines how much the individual's consumption changes with when his income is changed by one unit. ${ }^{11}$

This definition is e.g. used by Keneys, but I argue that this measure is a too narrow definition for the individual's marginal propensity to consume. When we now allow the individual to derive utility from his psychological consumption as in eq. (1), instead of his absolute consumption, it is a necessity to also revisit the definition of the individual's MPC.

\subsubsection{An Increased Permanent Income affects MPC}

The individual's closed form consumption function is the same as eq. (15):

$$
c_{\tau}=\gamma \Psi c_{\tau-1}+\eta \Psi \bar{c}_{\tau}-\eta \bar{c}_{\tau+1}^{p}+\left(1-\frac{\gamma}{1+r}\right) y_{\tau}^{p}
$$

Differentiating eq. (21) with respect to $y_{\tau}^{p}$ yields the traditional measure of an individual's MPC (we did exactly the same procedure in section 3.1 but never introduced the concept MPC); which is equal to:

$$
m p c=\frac{\partial c_{\tau}}{\partial y_{\tau}^{p}}=1-\frac{\gamma}{1+r} .
$$

Hence, if the individual would have had 1 unit higher permanent income, his consumption at time $\tau$ would change by $1-\frac{\gamma}{1+r}$ units. We can see that the individual's MPC depends merely on how much he cares about his previous consumption $(\gamma)$. This is also an individual's MPC in the model by Alessie and Lusardi (1997), hence $m p c \equiv m p c^{A \& L}$.

\footnotetext{
${ }^{11}$ One unit more of permanent income implies that each periods' income increases with one unit.
} 
The other extreme case is when $\gamma=0$, which corresponds to Hall's (1978) model of PIH. Then, it is easy to see that the individual's MPC is:

$$
m p c^{P I H}=\frac{\partial c_{\tau}}{\partial y_{\tau}^{p}}=1 .
$$

This implies if the individual's permanent income would by one unit higher, then consumption increases under Hall's (1978) model of PIH with the corresponding amount. Thus, (22) nests two models of the individual's traditional definition of the MPC given various values of $\gamma$.

It is a stated fact that individuals care to some degree about the consumption (income) of relevant others (e.g. Solnick and Hemenway (1998), Johansson-Stenman et al. (2002), Alpizar et al. (2005), and Andersson (2006)) The individual is said to experience a demonstration-effects when he compare his consumption level with the consumption level of his relevant others, $\bar{c}_{\tau}$. Given this, the individual's psychological consumption is affected by $\bar{c}_{\tau}$, but not his marginal propensity to consume in the traditionally way of discussing MPC (when the individual entertain a additive comparison utility). This, indicate the traditional definition of the MPC is to narrow, since it is merely affected by the individual's own permanent income, but we know at the same time that the permanent consumption of his relevant others also effect the individual's consumption. The traditional definition of the MPC originates from a notion that argues that the individual derives utility from his absolute consumption level. However, when we now allow psychological and sociological aspects to enter economic models we need to have a broader definition of the individual's MPC. I argue that we should also include the effect from the relevant others consumption, both the current $\left(\bar{c}_{\tau+1}\right)$ and future permanent consumption $\bar{c}_{\tau+1}^{p}$ in the definition of the MPC, since the effect from the individual's own permanent income on his consumption is only one of several effects. Therefore, I put forward a broader definition of the individual's MPC that takes into account the individual's relevant others' consumption. I introduce the individual's total MPC as:

The total MPC defines how much the individual's consumption changes with when his income is changed by one unit; in addition when the consumption the individual's relevant others increases with one unit

\subsubsection{The Consumption of Relevant Others affects MPC}

We assume that the structural change in the economy has a permanent effect on the consumption of the relevant others, both $c_{\tau}$ and $\bar{c}_{\tau}^{p}$ changes in the same direction. The individual's total MPC, with respect to a permanent increase in the consumption of the relevant others, i.e. his total MPC, is hence:

$$
m p c^{\text {total }}=\frac{\partial c_{\tau}}{\partial \bar{c}_{\tau}}+\frac{\partial c_{\tau}}{\partial \bar{c}_{\tau+1}^{p}}+\frac{\partial c_{\tau}}{\partial y_{\tau}^{p}}=1+\eta \Psi-\eta-\frac{\gamma}{1+r}
$$


where $\Psi<1$. With the assumptions that $\gamma>0$ and $0<\eta<1$, it is possible to formulate the following proposition:

Proposition 1. When the individual derives utility from both his own current and previous consumption in addition to the current consumption of his relevant others, is his MPC lower than if the individual merely has a habit formation behavior, as in Alessie and Lusardi (1997), while the MPC is highest in Hall's (1978) PIH model.

Proof 1. The inequality $1=m p c^{P I H}>m p c^{A \& L}=1-\frac{\gamma}{1+r}$ holds when $\gamma \in(0,1]$, since we have that $\frac{\gamma}{1+r}>0$. Furthermore, when $\gamma \in(0,1]$ and $\eta \in(0,1)$, we also have that $1+\eta(\Psi-1)-\frac{\gamma}{1+r}=m p c^{\text {total }}<m p c^{A \& L}=$ $1-\frac{\gamma}{1+r}$ holds since $\eta(\Psi-1)<0$. Hence, it is obvious that mpc ${ }^{P I H}>$ $m p c^{A \& L}>m p c^{\text {total }}$. Q.E.D.

Hence, when $\Psi<1, \gamma>0$ and $0<\eta<1$ we can conclude that the total MPC given a permanent consumption change of the relevant others the structure for these theories is $m p c^{P I H}>m p c^{A \& L}>m p c^{\text {total }}$.

Thus, if the individual has both a habit-formation behavior and cares to some degree about the consumption of his relevant others, his consumption is less sensitive to an increase in his permanent income and his relevant others' permanent consumption compared to if he merely has a habit-formation behavior and obviously if only his absolute consumption drives utility. This "smoothness" depends on that the individual does not wish to fall behind the consumption of his relevant others in the future, and therefore he adjusts his consumption level less. Hence, this model may then explain the "excess smoothness" phenomenon ${ }^{12}$ found in the consumption data better than earlier theories; which leaves room for further research.

\section{Concluding Remarks}

By looking at psychological and sociological arguments of how individuals derive their utility, I extend Alessie and Lusardi's (1997) consumption model, in which individuals merely have habit-formation behaviors, adding the notion that individuals also care about the consumption of his relevant others and derive a general closed form consumption function that nests the closed form consumption functions of either Hall's (1978), PIH or a habit-formation behavior such as in Alessie and Lusardi (1997) consumption models.

The extension of Alessie and Lusardi (1997) psychological consumption measures (that drives utility) implies that the consumption of relevant others affects the individual's consumption in two different ways. The individual's consumption $(i)$ decreases when the future permanent consumption of

\footnotetext{
${ }^{12}$ Read e.g. Deaton (1992) for further information of "excess smoothness" and "excess sensitivity".
} 
relevant others increase, and (ii) increases when the current consumption increases. Furthermore, a change in the consumption of the relevant others does not affects the individual's traditional MPC. However, I believe when economic models now also contain psychological and sociological aspects the traditional definition of the MPC is too narrow. I have shown that the traditional MPC is affected when the permanent consumption of the relevant others changes. However, I argue that the total MPC is lower compared to both Hall's (1978), and Alessie and Lusardi 1997 marginal propensities to consume. This is a consequence from that the individual does not wish to fall behind the consumption of his relevant others in the future. Furthermore, this model may then explain the "excess smoothness" better; which leaves room for further research.

Future research will benefit from having a panel data set of consumption and income of individuals or households. Then it will be possible to test if the consumption of individuals depends on both his own previous consumption and that of his relevant others, in addition to new information regarding own future income and that of relevant others (relaxing the assumption of perfect foresight). In some sense this is analogous with papers in the happiness literature, where empirical evidence suggests that the happiness of individuals is affected by the income level of relevant others; see e.g. Ferrer-i Carbonell (2005).

\section{References}

Abel, A. (1990). Asset prices under habit formation and catching up with the joneses. American Economic Review, 80:38-42.

Alessie, R. and Lusardi, A. (1997). Consumption, saving and habitformation. Economics Letters, 55(1):103-108.

Alonso-Carrera, J., Caballé, J., and Raurich, X. (2004). Consumption externalities, habit formation and equilibrium efficiency. Scandinavian Journal of Economics, 106(2):231-251.

Alpizar, F., Carlsson, F., and Johansson-Stenman, O. (2005). How much do we care about absolute versus relative income and consumption? Journal of Economic Behavior \&J Organization, 56(3):405-421.

Andersson, F. W. (2006). Is concern for relative consumption a function of relative consumption? Working paper No. 220, Department of Economics, University of Göteborg.

Carroll, C. D. (2000). Solving consumption models with multiplicative habits. Economics Letters, 68:67-77. 
Carroll, C. D., Overland, J., and Weil, D. N. (1997). Comparison utility in a growth model. Journal of Economic Growth, 2:339-367.

Deaton, A. S. (1992). Understanding Consumption. Clarendon Lectures in Economics. Clarendon Press, Oxford.

Duesenberry, J. S. (1949). Income, saving, and the theory of consumer behavior. Havard Univeristy Press, Cambridge, MA.

Elster, J. and Loewenstein, G. (1992). Utility from memory and anticipation. In Elster, J. and Loewenstein, G., editors, Choice over time, pages 213234. Russell Sage Foundation, New York.

Ferrer-i Carbonell, A. (2005). Income and well-being: An empirical analysis of the comparison income effect. Journal of Public Economics, 89(56):997-1019.

Frank, R. H. (1985). Choosing the right pond: Human behavior and the quest for status. Oxford Univeristy Press, Oxford.

Friedman, M. (1957). A theory of the consumption function. Princeton Univeristy Press, Princeton.

Hall, R. E. (1978). Stochastic implication of the life-cycle-permanent income hypothesis: Theory and evidence. The Journal of Political Economy, 86(6):971-987.

Johansson-Stenman, O., Carlsson, F., and Daruvala, D. (2002). Measuring future grandparents' preferences for equality and relative standing. The Economic Journal, 112(479):362-383.

Keynes, J. M. (1936). The General Theory of Employment, Interest and Money. Macmillan, London.

Runciman, W. G. (1966). Relative deprivation and social justice. University of California Press, Berkeley.

Schor, J. B. (1998). The overspent American. Upscaling, downshifting, and the new consumer. Basic Books, New York.

Scitovsky, T. (1992). The Joyless Economy: The Psychology of Human Satisfaction. Oxford University Press, New York, Oxford.

Solnick, S. J. and Hemenway, D. (1998). Is more always better?: A survey on positional concerns. Journal of Economic Behavior 83 Organization, 37(3):373-383.

Veblen, T. (1934). The theory of the leisure class. Morden Library, New York. 
Wendner, R. (2002). Habits: Multiplicative or subtrative? Mimeo, Department of Economics, Graz University.

\section{Appendix A}

We know that under certain assumptions the individual's MRS is equal to (the same as eq. (10)):

$$
\frac{\frac{\partial u\left(c_{t+1}^{*}\right)}{\partial c_{t+1}^{*}}-\gamma \beta \frac{\partial u\left(c_{t+2}^{*}\right)}{\partial c_{t+2}^{*}}}{\frac{\partial u\left(c_{t}^{*}\right)}{\partial c_{t}^{*}}-\gamma \beta \frac{\partial u\left(c_{t+1}^{*}\right)}{\partial c_{t+1}^{*}}}=1 .
$$

Proposition 2. The only admissible time series of psychological consumption, $\left\{c_{\tau}^{*}\right\}_{\tau=t}^{T}$, that satisfies eq. (25) when $T \rightarrow \infty$ is:

$$
\frac{\partial u\left(c_{t}^{*}\right)}{\partial c_{t}^{*}}=\frac{\partial u\left(c_{t+1}^{*}\right)}{\partial c_{t+1}^{*}}=\frac{\partial u\left(c_{t+2}^{*}\right)}{\partial c_{t+2}^{*}}=\Omega, \quad \forall t
$$

and where $\Omega$ is a constant.

Proof 2. If the marginal utility of psychological consumption is not constant over time and $\frac{\partial u\left(c_{t+1}^{*}\right)}{\partial c_{t+1}^{*}} \neq \frac{\partial u\left(c_{t}^{*}\right)}{\partial c_{t}^{*}}$, it is possible calculate $\frac{\partial u\left(c_{t+2}^{*}\right)}{\partial c_{t+2}^{*}}$. In order for eq. (25) to be satisfied

$$
\frac{\partial u\left(c_{t+2}^{*}\right)}{\partial c_{t+2}^{*}}=\frac{1+\gamma \beta}{\gamma \beta} \frac{\partial u\left(c_{t+1}^{*}\right)}{\partial c_{t+1}^{*}}-\frac{1}{\gamma \beta} \frac{\partial u\left(c_{t}^{*}\right)}{\partial c_{t}^{*}} .
$$

Eq. (27) is a second order difference equation and its general solution is:

$$
\frac{\partial u\left(c_{t+n}^{*}\right)}{\partial c_{t+n}^{*}}=A+B\left(\frac{1}{\gamma \beta}\right)^{n},
$$

where $A$ and $B$ are arbitrary constants. When the individual has a habit formation behavior it implies that $0<\gamma \beta<1$ and then eq. (28) shows that the individual's marginal utility of psychological consumption is growing over time. When the individual's utility function is concave it means that the individual's psychological consumption, $c_{t+n}^{*}$, reduces over time and implies that the individual's absolute consumption also reduces over time. This is not an utility maximization, i.e. (2) is not maximized. Hence, proposition 2 is true, and we can formulate Lemma 1. Q.E.D. 